\title{
MORE FORESIGHT
}

\section{Dear Reader,}

Electric cars have long since advanced from being just an ecological fig leaf, and are now being presented as a logical extension to the existing product portfolio. But it is becoming increasingly certain that the combination of an electric machine and an internal combustion engine - either as a range extender or a hybrid - is likely to be the more successful concept over the next few years from the point of view of customer acceptance. Nevertheless, it is good that the number of electric cars is continuing to rise, as only in this way can the technology be sustainably introduced into the market. At the same time, it is to be hoped that the $\mathrm{CO}_{2}$ balance in the German electricity mix will significantly improve from the current figure of approximately $560 \mathrm{~g} / \mathrm{kWh}$. Only then would electric mobility really make sense environmentally.

All this is nothing really new. What is new, on the other hand, is that one manufacturer, Hyundai, is suddenly presenting a fuel cell vehicle with the firm intention of also launching it on the market within a year. Other OEMs are equally in a position to mass produce the doubtlessly efficient fuel cell. Mercedes also has the technology to begin series production in 2015. But the company prefers to wait: According to the Stuttgart-based carmaker, the infrastructure will not be available until 2017 at the earliest.

And precisely that is the snag, as there seems to be a lack of determination among politicians, energy providers and infrastructure operators. There is plenty of lip service, but it is obviously more convenient and more popular to force manufacturers to make ever greater efforts in exhaust treatment and fuel consumption than to address the - admittedly complex - problems of alternative fuels and their distribution network.
And yet, solutions are readily available. Producing hydrogen in larger quantities from regenerative energy is technically feasible - provided there is a will to do so. And hydrogen is produced in relevant quantities as a waste product in the chemical industry, for example in chlorine production. How this waste product can be cleaned and used as a fuel is shown by the example of Frankfurt/ Main: Its public hydrogen filling station uses hydrogen that is cleaned and supplied by the chemical company Infraserv. The potential to produce hydrogen in large quantities with zero emissions, or at least with low emissions, does indeed exist. However, launching this technology sustainably on the market requires considerable effort in expanding the distribution network. And manufacturers and suppliers cannot carry this burden alone. Instead, it requires political foresight and backbone to prevent an efficient and forward-looking drive technology from being permanently sidelined.

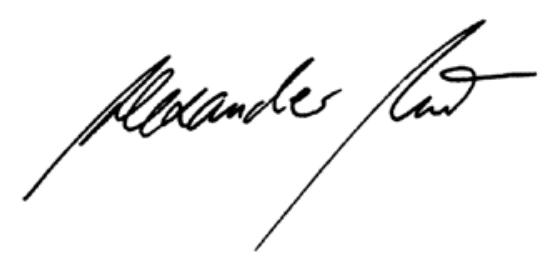

DR. ALEXANDER HEINTZEL, Editor in Chief Wiesbaden, 16 September 2013

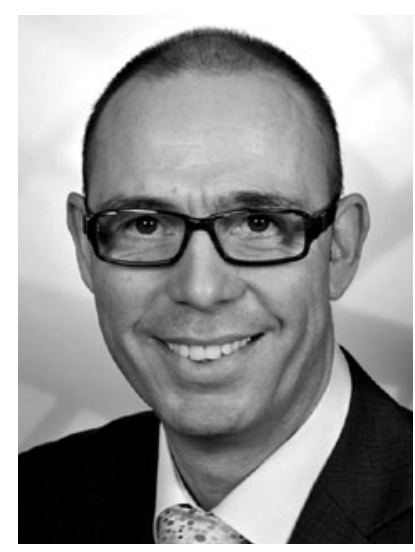

